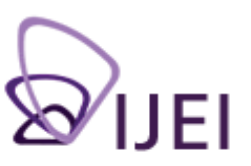

International Journal for Educational Integrity

\title{
Review \\ Originality, imitation and plagiarism: Teaching writing in the digital age
}

\author{
Caroline Eisner and Martha Vicinus (Eds.). (2008). \\ Ann Arbor: The University of Michigan Press.
}

\author{
Ruth Walker \\ The University of Wollongong \\ rwalker@uow.edu.au
}

At one stage in the anthology Originality, imitation and plagiarism: Teaching writing in the digital age, it is pointed out that students 'worry' about plagiarism in the same way that they worry about engaging in file-sharing or illegally downloading software. That is - they don't. The attendant risks of getting caught or becoming vulnerable to a computer virus are recognised as the potential bad outcomes, but have become steadily normalised. This analogy, with its viral undertones, nicely expresses the quandary at the heart of a discussion of students' writing in the digital age, where the expanded possibilities of online research seem to not only model but to openly invite copying practices. It is increasingly difficult for student writers to negotiate the competing pressures of popular media culture, which actively complicate the concepts of originality and imitation, and the pedagogical directives to avoid plagiarism in their academic work. The issue is not as clear cut as some plagiarism policies might suggest, as the complexities of fair use and copyright of online material are being debated both in and out of the academy. This anthology explores the blurred lines of the often confusing and contradictory approaches to writing in the digital age, with individual essays addressing - through a range of disciplines and technologies - the central question of how ethical research and writing standards and practices can be fostered while simultaneously taking advantage of the opportunities provided by new technologies.

To suggest that the Internet alone is responsible for the perceived rise in plagiarism is too technologically determinist a position. Instead, the co-editors Caroline Eisner and Martha Vicinus point out that the public debates about plagiarism have coincided with anxieties about the increased access to copyrighted material, in addition to the recognition, prompted by postmodern literary theory, that nothing is wholly original, that we depend on remixing, reusing and reproducing the past (p. 1). However, it is also an inescapable truth that the Internet has added a new element to student writing and research practices. As Kim Waldon and Alan Peacock point out in their chapter about the economies of plagiarism, the move from handwriting to word processing, for which 'copy and paste' is an integral function, has amplified acts of compilation because it has changed the economy of effort (p. 138-139). But the issue of plagiarism does not rest with the increased availability of new media or the technological proficiency of student writers: in fact, evidence of the weakness of their digital savviness can be found in students' lack of critical judgement about the relative quality of material found online, and also in their lack of recognition that, just as easy as it may be to find and copy information from the Internet, it is equally easy for teachers to detect this copying with a judicious use of google search for exact phrase matching.

The International Journal for Educational Integrity is available online at:

http://www.ojs.unisa.edu.au/journals/index.php/IJEI/

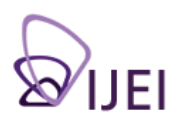


A number of essays in this collection address the rise of commercial technological 'solutions' to plagiarism, such as that offered by Turnitin, and provide a refreshing change of focus from student deficit or bad writing practices, common to most discussions of plagiarism. Doubts about the benefits of these commercial plagiarism detection services emphasise the ways that the obsession with plagiarism prevention can actively damage trust between teacher and student, as risk management is prioritised at the expense of good teaching and learning practices. Linda AdlerKassner, Chris Anson and Rebecca Moore Howard recommend a reframing of the discussion of plagiarism, students and technology in universities and in the media. Rather than focusing on theft and morality, they urge that teachers encourage students to understand different genres and contexts, to acknowledge the existence of "different discursive communities with different practices and activities" (p. 240). Instead of policing student writing, the emphasis should be on developing better assignments and understandings of writing, which would diminish the perceived need for control mechanisms such as Turnitin.

At different points in the anthology useful suggestions are made about how to creatively structure assessment tasks that don't facilitate easy plagiarism, moving away from general open-ended essay questions that are all too easy to find material about online. Indeed, Lynn Z. Bloom argues that "it is far easier, more intellectually interesting, and more ethically satisfying to prevent plagiarism than to track it down" (p. 209). Her suggestions for 'plagiarism-proof' assignments rest on the development of 'insider writing', where students inside specific classes are actively engaged in setting the parameters for the assignment at hand, rather than approaching it as passive consumers. Another paper proposes an 'i-map' model, which shifts the emphasis away from a single-point content-led submission of a completed assignment to one which encourages students to track their research activities and thinking processes as they build on source material. This ongoing and often collaborative approach to assignments can usefully provoke broader discussion about the ownership of knowledge and the uses of information. However, a paper on new collaborative writing opportunities offered by wikis, discusses the implications of this kind of writing on the role of the single author. As Amit Ray and Ehradt Graeff argue, open access in the creation and editing of web content in platforms like Wikipedia not only decentralises the role of any individual writer in the creation of texts, but turns all texts into unstable entities. This, they point out, has had profound implications for the production, modification and dissemination of information and knowledge via the Internet.

Overall, this collection of essays is fascinating for the way it not only canvasses enduring pedagogical concerns about originality, imitation and plagiarism, but for the way if offers a snapshot of how students and their teachers are negotiating the impact of their rapid appropriation of information and communication technologies at the beginning of the 21 st century. Although research, writing and submission strategies are changing for both students and teachers, the kind of assignments expected from students hasn't adapted as quickly. This anthology usefully moves beyond the adversarial approach to plagiarism common to educational contexts, to a consideration of copyright and intellectual property issues debated in cultural and legal arenas. In so doing, it opens up a discussion of how, in the digital age, more effective writing tasks can be integrated into the teaching of intellectual integrity.

\section{Reviewer}

Ruth Walker teaches academic writing at the University of Wollongong, collaborating with Faculties to develop student-centered approaches to the development of academic literacies. She works with transnational programs in Hong Kong, and is developing a research project on international student performativity and plagiarism. 